\title{
The Horn Technique for Nasal Tip Support in Rhinoplasty
}

\author{
Luiz Carlos de Melo Barboza ${ }^{1}$ Maíra Garcia Martins ${ }^{10}$ Carlos Alberto Caropreso ${ }^{1}$ \\ José Luiz Teixeira Rodrigues ${ }^{1}$ André Baraldo Rodrigues ${ }^{1}$
}

${ }^{1}$ Department of Otorhinolaryngology, Universidade de São Paulo, São Paulo, SP, Brazil

Int Arch Otorhinolaryngol 2021;25(3):e383-e385.
Address for correspondence Maíra Garcia Martins, MD, Departamento de Otorrinolaringologia, Faculdade de Medicina da Universidade de São Paulo, Av. Dr. Enéas de Carvalho Aguiar, 255 - $6^{\circ}$ andar - sala 6167; São Paulo, SP 05403-000, Brasil (e-mail: mairagarciamartins@gmail.com).

\begin{abstract}
Keywords

- nasal tip

- rhinoplasty

- plastic surgery

Introduction The predictability of nasal tip projection and rotation after aesthetic surgery is a challenge. Tongue-in-groove (TIG) is an effective technique to control tip projection and rotation, but there may be a small loss of projection and rotation of the tip lobe due to lack of support between the anterior septal angle and the domus, since this region is sustained by medial crusts suture-linked and interdomus sutures.

Objective To describe a new surgery technique in an attempt to correct the lack of support for the nasal tip after lowering the nasal dorsum.

Methods The horn technique consists in preserving a square of cartilage during the removal of the nasal dorsum and septum excess in patients with long and projected nose. This piece will give greater support to the TIG technique and greater predictability of the rotation and projection of the nasal tip.

Results Between 2016 and 2018, 50 patients with long and projected noses were submitted to the "horn technique" surgery. They were submitted to the TIG technique associated to the horn technique. A retrospective review of the preoperative and postoperative photographs ( 3 months to 1 year) of these patients treated with the horn technique were analyzed and showed better support of the nasal tip.

Conclusion The horn technique provides greater support to the projection and rotation of rhinoplasties in patients with long and projected nose.
\end{abstract}

\section{Introduction}

The nasal tip approach in facial aesthetic surgery is still a challenge in most cases, it requires care and experience of the surgeon. The tip rotation (TR) and tip projection (TP) are essential to a successful rhinoplasty. Rethi ${ }^{1}$ proposed in 1934 a technique called "tongue-in-groove" (TIG) for the nasal tip approach. It consists in advancing cephaloposteriorly the medial crura replacing the caudal septum into the space created between them. The created groove may vary, the depth of the medial crural pocket should be greatest at the dorsal or anterior aspect to a greater degree of upward nasal tip rotation, and it should be placed posteriorly to inferiorly rotate the nasal tip or to correct excess columellar show. The caudal septum may be variably adjusted, depending on the correction required. When the caudal septum is placed into the groove, the medial crura may be advanced anteriorly toward the dome cartilages and fixed with sutures in this position. This surgical received

October 22, 2018

accepted

February 17, 2020

published online

September 24, 2020
DOI https://doi.org/ 10.1055/s-0040-1709193. ISSN 1809-9777.

\footnotetext{
(c) 2020. Fundação Otorrinolaringologia. All rights reserved.

This is an open access article published by Thieme under the terms of the Creative Commons Attribution-NonDerivative-NonCommercial-License, permitting copying and reproduction so long as the original work is given appropriate credit. Contents may not be used for commercial purposes, or adapted, remixed, transformed or built upon. (https://creativecommons.org/ licenses/by-nc-nd/4.0/) Thieme Revinter Publicações Ltda., Rua do Matoso 170, Rio de Janeiro, RJ, CEP 20270-135, Brazil
} 
technique has been used in both primary and secondary rhinoplasties. $^{2}$

The TIG technique is rarely performed isolated, some other maneuvers are necessary to guarantee a well-defined nasal tip. In droopy tip cases, TIG might provide insignificant projection and requires additional maneuvers ${ }^{2}$ due to the lack of support to perform the TIG at a desired height in the nasal septum after lowering the nasal dorsum, and when performing TIG on a septal extension there may be a slight loss in rotation and support of the long-term nasal tip. With the intention of maintaining the rotation and guaranteeing better support, we have created the horn technique. It attempts to correct the lack of support for the nasal tip after lowering the nasal dorsum, providing a greater support for the TIG. The purpose of the present study was to report our experience in 50 cases submitted to rhinoplasty using TIG associated to the horn technique.

\section{Methods}

From August 2016 to January 2018, we have applied the horn technique in 50 cases of patients with long and projected noses. They were submitted to the TIG technique associated to the horn technique. Approved by the ethics committee (approval number 3.755.316), a free and informed consent form was obtained from all involved patients.

Technique description: the open approach was used in all patients. During the removal of the nasal dorsum and septum excess, in patients with long and projected nose, a square of cartilage was preserved in the anterior septal angle region (-Figs. 1 and 2). The size of the fragment may be variable according to the projection desired and depending on the height of the remaining septum. This piece will give greater support to the TIG technique and greater predictability of the rotation and projection of the nasal tip.

The aesthetic comparative result of the preoperative and postoperative photographs was analyzed, as well as the degree of satisfaction of the patients. (-Figs. 3, 4 and 5).

In the postoperative period, the patients answered a questionnaire about the degree of satisfaction that included the following questions: Are you satisfied with the aesthetic result of your surgery? Do you consider your nose prettier after surgery? Do you have any complaints regarding the outcome of the surgery?

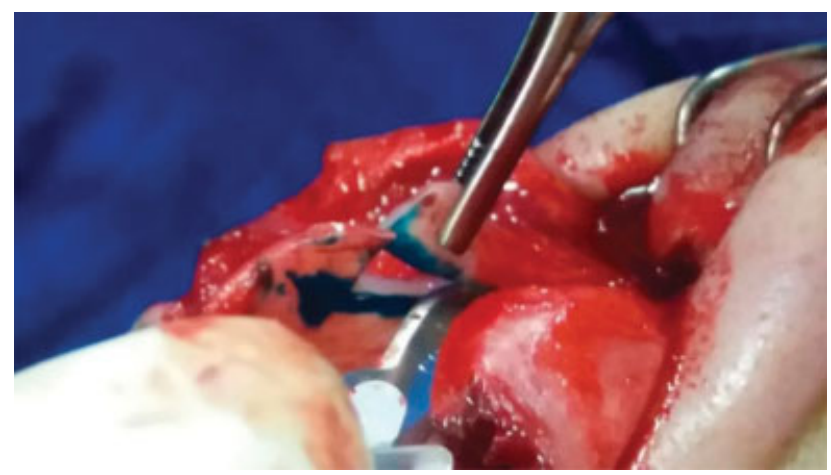

Fig. 1 Initial removal of the nasal dorsum, preserving a square on the distal septum.

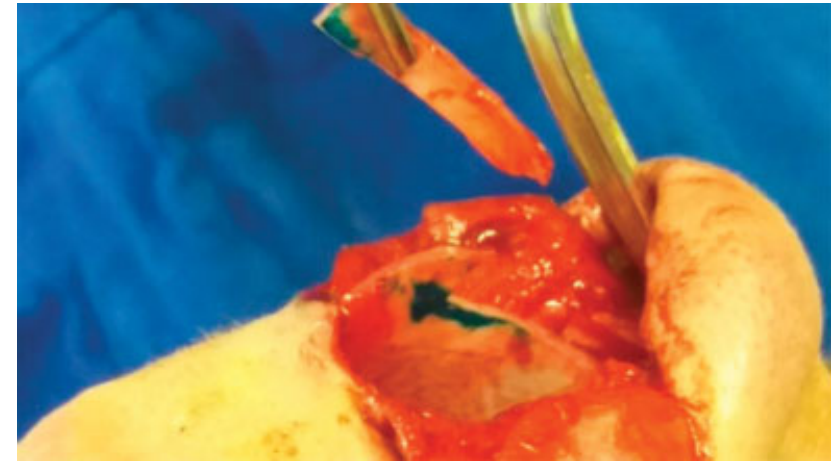

Fig. 2 The square preserved in the distal septum like a "horn," after removal of the dorsum.

\section{Results}

The horn technique was applied in 50 patients, with age ranging from 20 to 44 years old. High degree of satisfaction was reported by all patients who underwent the surgical horn technique. No complications were observed. They kept adequate nasal tip support in the late postoperative period of 6 months. Patients were questioned about possible complaints and did not show any complaints regarding postoperative tip ptosis.

\section{Discussion}

One of the studies with the largest number of patients submitted to rhinoplasty by the TIG technique was published

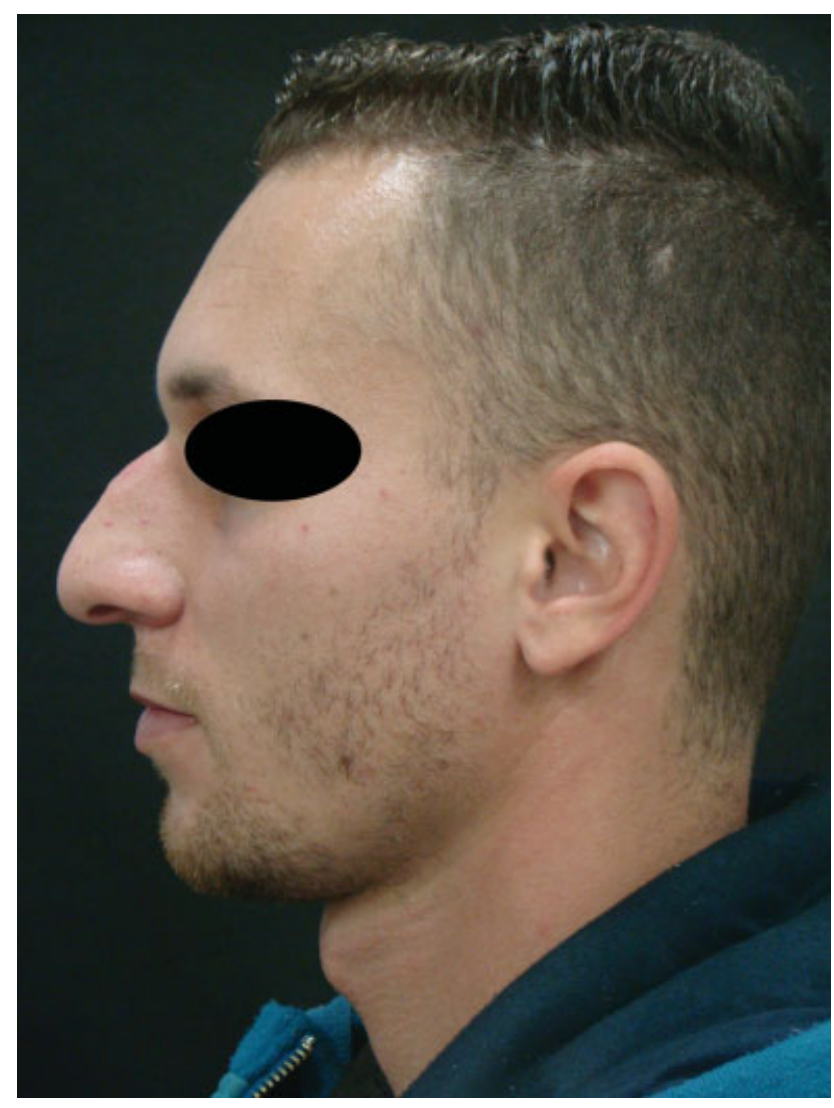

Fig. 3 Before the surgery. 


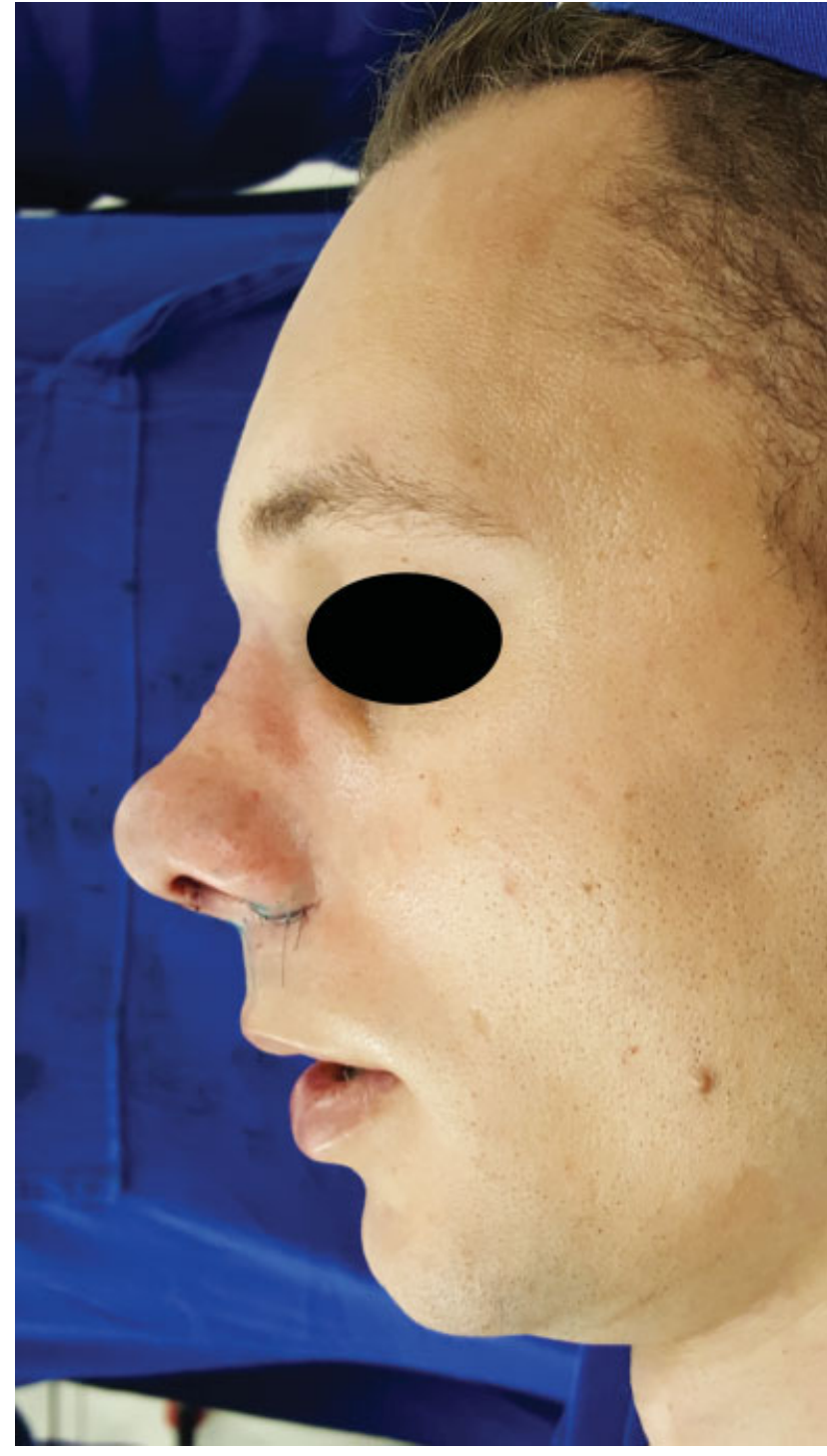

Fig. 4 Result after surgery.

by Kridel et al. ${ }^{3}$ The authors revised the records of 287 patients who underwent TIG rhinoplasties and satisfactory to excellent results were reported by $97 \%$ of the patients.

Although the TIG technique has shown long-lasting results, it is rarely performed isolated. These other techniques used together may interfere with the final result.

In a comparative study between techniques, Dobratz et $\mathrm{al}^{4}$ showed the alteration of the nasal tip in evolution of short and late postoperative period. The authors emphasized the importance of supporting structures to avoid temporal remodeling and they cited the reduction of the dorsal cartilaginous septum as a common alteration of a minor tip support mechanism. Kadakia et $\mathrm{al}^{5}$ described a variation of the TIG technique for endonasal rhinoplasty in 12 patients. The authors used a permanent suture buried in small columellar skin incisions. No complications were observed during the follow-up period and the modified TIG technique was considered useful and quick.

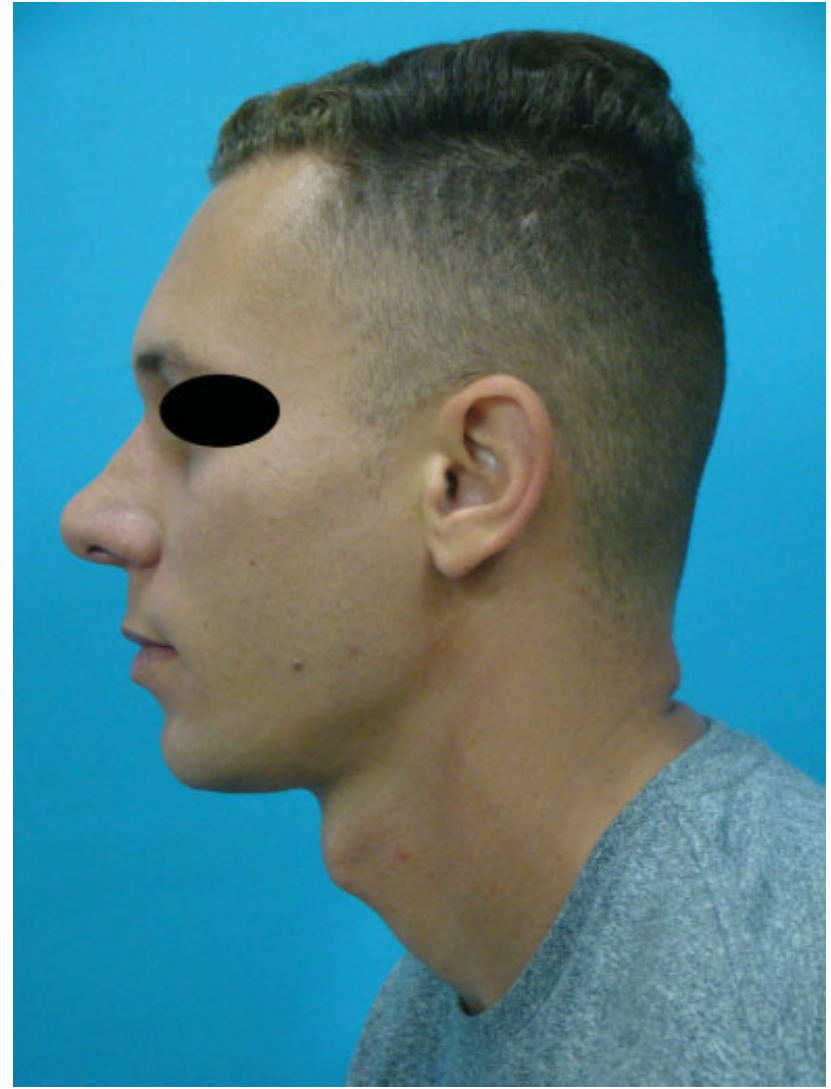

Fig. 5 Result 6 months after surgery.

Our results showed that the preservation of the square cartilage in the anterior septal angle region used in the horn technique may be a good option to correct the lack of support for the nasal tip after lowering the nasal dorsum.

\section{Conclusions}

The horn technique, associated to the TIG technique, provides greater support to the projection and rotation of rhinoplasties in patients with long and projected nose.

\section{Conflict of Interests}

The authors have no conflict of interests to declare.

\section{References}

1 Rethi A. Operation to shorten an excessively long nose. Rev Chir Plast 1934;2:85-87

2 Datema FR, Lohuis PJ. The Tongue-in-Groove Technique in Primary and Revision Rhinoplasty. Facial Plast Surg 2016;32(04): 416-423

3 Kridel RW, Scott BA, Foda HM. The tongue-in-groove technique in septorhinoplasty. A 10-year experience. Arch Facial Plast Surg 1999;1(04):246-256, discussion 257-258

4 Dobratz EJ, Tran V, Hilger PA. Comparison of techniques used to support the nasal tip and their long-term effects on tip position. Arch Facial Plast Surg 2010;12(03):172-179

5 Kadakia S, Ovchinsky A. Modified Endonasal Tongue-in-Groove Technique. Facial Plast Surg 2016;32(05):569-575 